\title{
Alinhamento entre uso de instrumentos do Sistema de Controle Gerencial e inovação de produtos e processos
}

\section{Alignment between the use of Management Control System instruments and product innovation and processes}

\author{
IAGO FRANÇA LOPES* \\ ILSE MARIA BEUREN** \\ GISLENE DAIANA MARTIN***
}

\section{RESUMO}

Este estudo objetiva verificar o alinhamento da intensidade de uso de instrumentos do Sistema de Controle Gerencial com o nível da inovação de produtos e processos. Para tanto, pesquisa descritiva com abordagem quantitativa foi realizada a partir de um levantamento com gestores de empresas incubadas. Os resultados mostram que elas apresentam nível semelhante no lançamento de novos produtos e modificações naqueles já existentes, mas diferem entre si na liderança de mercado no lançamento de novos produtos. A entropia informacional reforça essa constatação, pois liderança de mercado no lançamento de novos produtos apresentou maior dispersão, sugerindo que as incubadas focalizam-se mais em suas necessidades iniciais. Quanto aos instrumentos gerenciais, projeções de fluxo de caixa e orçamento operacional revelam capacidade para alinhar o processo inovador, já que apresentam médias elevadas e peso

* Mestre em Contabilidade pela Universidade Federal de Santa Catarina - UFSC. iagofrancalopes@gmail.com

** Doutora em Controladoria e Contabilidade pela FEA/USP. Professora do Programa de Pós-Graduação em Contabilidade da Universidade Federal de Santa Catarina. ilse.beuren@ gmail.com

***Bacharel em Ciências Contábeis pela Universidade Federal de Santa Catarina - UFSC. gislenedaiana@gmail.com 
informacional pouco disperso. Porém, definição de metas estratégicas e plano de portfólio de produtos apresentam médias superiores e peso informacional menos disperso, denotando que os gestores usam esses instrumentos com intensidade no desenvolvimento das atividades de inovação. Conclui-se que há evidências de alinhamento entre intensidade de uso de instrumentos gerenciais e nível de inovação de produtos e processos nas empresas pesquisadas, mas esses construtos requerem mais pesquisas para sua confirmação empírica.

Palavras-chave: Instrumentos do Sistema de Controle Gerencial; nível de inovação; empresas incubadas

\section{Abstract}

The goal of this study is to verify the alignment of the intensity of use of Management Control System instruments with the level of innovation of products and processes. Thus, descriptive research with quantitative approach was conducted from a survey with managers of incubated companies. The results show that incubated companies present similar level in launching new products and modifications to existing products, but differ in market leadership in launching new products. The informational entropy reinforces this finding, once market leadership in launching new products showed greater dispersion, suggesting that incubated companies focus more on their initial needs. As for management tools, cash flow projections and operating budget reveal ability to align the innovative process, since they have high means and little dispersed information weight. However, defining strategic goals and product portfolio plan have higher mean and less dispersed information weight, indicating that managers use these instruments with intensity in the development of innovation activities. It is concluded that there are evidences of alignment between the intensity of use of management instruments and level of products innovation and processes in the companies surveyed, but the constructs require more research for empirical confirmation.

Keywords: Management Control System instruments; level of innovation; incubated companies. 


\section{INTRODUÇÃo}

Paladino (2010) afirma que as empresas brasileiras estão buscando alcançar cada vez mais níveis elevados de competitividade para enfrentar a concorrência. Investimentos contínuos em qualidade, produtividade e inovação dão visivelmente aos negócios essa condição (LOPES; BEUREN, 2016). Tal processo possibilita integrar e balancear competências relacionadas a diversas funções da organização, como Pesquisa, Desenvolvimento e Inovação (PD\&I) e Marketing (PALADINO, 2010).

D'Avila e Oliveira (2002) descrevem que o desenvolvimento contínuo das empresas e o aumento da competitividade exigem a implementação de mudanças, assim como o conhecimento de novas ferramentas de trabalho por parte dos gestores, de modo a possibilitar a obtenção de resultados positivos. Nesse sentido, Frezatti et al. (2012) alertam que a inovação tem forte dependência da estratégia geral adotada pelas empresas, relacionando-se direta ou indiretamente com ela.

O uso de instrumentos do Sistema de Controle Gerencial (SCG) alinhado ao processo de inovação constitui-se em um mecanismo importante para o crescimento das empresas. A inovação é um mecanismo para criar mudanças com o intuito de aumentar o potencial econômico e social da organização (DRUCKER, 1999). Os controles gerenciais, por sua vez, auxiliam os gestores na otimização dos recursos e fornecem informações relevantes à tomada de decisões. Além disso, os controles gerenciais são parte de um sistema social dinâmico e exercem influência positiva sobre o processo de gestão da inovação (SIMONS, 1990).

Portanto, esses dois mecanismos favorecem o desenvolvimento econômico e social e o aumento da competitividade das organizações. No entanto, estudos anteriores destacam ausência de instrumentos de controle gerencial associados ao processo de inovação. Oyadomary et al. (2010) aduzem que um dos motivos é a existência de conflitos entre o uso de SCG relacionados com a inovação, uma vez que as empresas necessitam inovar para obter resultados no longo prazo, mas precisam controlar os recursos de curto prazo para cumprir as obrigações correntes. Observa-se que é baixo o nível de investimentos em inovação no Brasil, em razão da desconfiança por 
parte das empresas de que esse processo possa contribuir para o aumento da sua competitividade e crescimento econômico (LOPES; BEUREN; DAMETTO, 2015).

Os gestores necessitam de instrumentos de controle gerencial que possibilitem o planejamento e a execução de suas atividades (FREZATTI et al., 2012). De acordo com os mesmos autores, a elaboração do planejamento é um processo complexo, visto que envolve diversas áreas e vários níveis hierárquicos da organização, implicando também decisões estratégicas e táticas. As estratégicas geralmente são voltadas para o longo prazo, ao passo que as táticas para o curto prazo (FREZATTI et al., 2012).

Por outro lado, conforme Frezatti et al. (2012), a inovação nem sempre é implantada pelas empresas de maneira estruturada, o que pode impactar o direcionamento dos negócios e demais decisões. Todavia, o planejamento e o controle devem permear o processo de gestão da inovação. Dessa forma, conforme Frezatti et al. (2012, p. 2), essas etapas passam a "fazer parte do modelo de gestão das organizações, sendo relevante a maneira como elas desenvolvem e controlam o processo".

Com base no exposto elaborou-se a seguinte questão-problema: qual o alinhamento da intensidade de uso dos instrumentos de planejamento financeiro, planejamento estratégico e planejamento de recursos humanos com o nível de inovação de produtos e processos em empresas incubadas? Assim, o objetivo deste estudo é verificar o alinhamento da intensidade de uso de instrumentos do Sistema de Controle Gerencial com o nível de inovação de produtos e processos em empresas incubadas.

Paladino (2010) alerta que no Brasil são escassas as pesquisas que abordam a temática de gestão da inovação empresarial. Essa categoria de gestão possibilita às organizações ganhos de novos mercados e aumento nos resultados financeiros. Este estudo, no aspecto teórico, pretende investigar as abordagens dessa temática no campo teórico-empírico. Já no aspecto prático, busca apresentar aos gestores alternativas que possam contribuir para a efetividade do processo de gestão da inovação empresarial por meio de instrumentos do SCG. 


\section{REFERENCIAL TEÓRICO}

\subsection{Instrumentos do Sistema de Controle Gerencial}

O controle gerencial constitui-se em um mecanismo utilizado pelas organizações para medir e avaliar o desempenho dos seus diferentes setores (WELSCH; HILTON; GORDON, 1988). O propósito é alcançar os objetivos, metas e padrões por elas estabelecidos (ANTHONY; GOVINDARAJAN, 2008). Tal controle está intimamente ligado às funções administrativas como, por exemplo, planejamento, organização e execução, e possibilita mudanças e melhorias, pois permite que as corporações atinjam melhor grau de eficiência, eficácia, economicidade e efetividade (ATTIE,1998).

Berry, Broadbent e Otley (2005) definem controle gerencial como o processo que ocorre num ambiente de mudança capaz de guiar a organização para padrões viáveis de atividades, o que é entendido como uma visão mais contemporânea da definição de Simons (1995a), conforme Frezatti et al. (2012). O processo de controle, segundo Mendonça (2011), deve estabelecer objetivos ou padrões de desempenho num primeiro momento, em seguida avaliar ou mensurar o desempenho atual, depois compará-lo com os objetos ou padrões estabelecidos, para então possibilitar a tomada de ação corretiva com vistas a corrigir possíveis desvios ou anormalidades.

Esse processo, de acordo com Merchant e Van der Stede (2007), ocorre por meio de três ciclos - de planejamento estratégico, de orçamento de capital e de orçamento propriamente - e implica a existência de práticas e instrumentos de controle gerencial. As práticas de controle gerencial, conforme Cruz, Frezatti e Bido (2015), são sistemas de medição usados para observar e analisar a mutação de informações que os gestores consideram ser de nível estratégico. Já os instrumentos são definidos por Merchant e Van der Stede (2007) como artefatos que contribuem, apoiam e viabilizam os objetivos almejados pelas organizações.

Observa-se a existência de controle quando sistemas de controle gerencial estão presentes (SIMONS, 1995a). Estes se compõem de “[...] rotinas formais baseadas em informações e procedimentos que os gestores se utilizam para manter ou alterar modelos nas atividades organizacionais" (SIMONS, 1995a, p. 5). Assim, conforme o 
autor, os objetivos são orientados para as atividades, os indivíduos têm autonomia e são avaliados pelos resultados. Nesse processo é importante estabelecer metas que permitam verificar se os gestores estão na direção correta para atingir o que foi estabelecido pela organização (FREZATTI et al., 2012).

A partir das definições apresentadas, infere-se que o Sistema de Controle Gerencial (SCG) é utilizado pelos gestores para assegurar que a estratégia estabelecida pela organização seja posta em prática e que os objetivos estipulados sejam alcançados de maneira eficiente e eficaz, com vistas a aprimorá-los quando necessário (BELTRAMI; GOMES; ARAÚJO, 2013). Para Simons (1990), são procedimentos e rotinas formalizadas que usam informações para manter ou alterar padrões nas atividades organizacionais.

Nessa perspectiva, Beuren e Oro (2014) aduzem que os controles formais contribuem para o processo de gestão da inovação ao fornecer informações quanto ao andamento da produção, à qualidade dos produtos e ao retorno dos investimentos, evidenciando a necessidade de ajustes periódicos que podem resultar na implementação de estratégias de diferenciação e inovação de produtos. Isso implica alinhamento do uso de instrumentos do Sistema de Controle Gerencial com o nível de inovação em organizações.

\subsection{Tipologias de inovação}

O processo de inovação se autossustenta fora dos padrões predeterminados (TIDD; BESSANT; PAVITT, 2008). A inovação, de acordo com esses autores, consiste em uma combinação de boas ideias, equipe motivada e uma compreensão acerca da necessidade demandada pelo mercado de atuação; não se trata apenas de uma nova invenção, mas do desenvolvimento e exploração de novos conhecimentos e oportunidades.

Carvalho, Reis e Cavalcante (2011, p. 25) advertem que inovar é diferente de inventar, pois nem toda invenção ou nova criação é inovada ou renovada; do mesmo modo, nem toda inovação é necessariamente uma invenção, pode constituir-se num processo de mudança positiva de algo já criado. Para Sarkar (2007), inovar é sinônimo de renovar ou alterar positivamente. A inovação representa 
um mecanismo de mudanças, com dimensões competitivas, cujo objetivo é prolongar a vida de uma organização (FREEMAN, 2004).

Tidd, Bessant e Pavitt (2008) apontam quatro categorias de inovação, conhecidas como 4Ps: de produto, de processo, de posição e de paradigma. A primeira corresponde à mudança dos produtos oferecidos por uma organização; a segunda refere-se à mudança na forma como são oferecidos; a terceira consiste na mudança do contexto em que são introduzidos; e a quarta implica a mudança das ideologias que orientam a companhia.

Do ponto de vista das tipologias, o Ministério de Ciência, Tecnologia e Inovação - MCTI (BRASIL, 2011) classifica as inovações tecnológicas em duas categorias: inovação de produto e inovação de processo. Essas atividades são um conjunto de diligências científicas, tecnológicas, organizacionais, financeiras e comerciais, incluindo o investimento em novos conhecimentos. A inovação tecnológica é, de acordo com Reis (2004), o principal fator de transformações nas empresas e no mundo, tornando-se essencial para o desenvolvimento de estratégias competitivas e, consequentemente, para maior crescimento e desenvolvimento sustentável.

Inovação em produto, conforme a Pesquisa de Inovação (PINTEC) (IBGE, 2012), ocorre quando suas características básicas diferem de todos os produtos já oferecidos pela empresa. Para a Organização de Cooperação e Desenvolvimento Econômico (OCDE), "é a introdução de um bem novo ou significativamente melhorado em relação às suas características ou usos previstos" (OCDE, 2005, p. 57). Já para Dougherty (2004, p. 341), “constitui-se num novo entendimento do mercado e da tecnologia da empresa", que deve ser incorporado por ela, agregando valor aos produtos que já oferece (LOPES; BEUREN, 2016).

Inovação em processo, segundo Van de Ven e Poole (2000), consiste na adoção de novas ideias desenvolvidas por pessoas que mantêm relações com outras para atingir resultados desejados. Essas ideias provocam mudanças nos contextos institucional e organizacional com o intuito de aperfeiçoar a produção do bem/serviço já comercializado e produzir benefícios para o processo produtivo, como redução da fadiga humana, aumento da produção e redução de custos, entre outros. 
Inovação organizacional, conforme Lopes e Beuren (2016), caracteriza-se pela aplicação de novas técnicas de gestão ou de mudanças relevantes na empresa e em suas relações externas com o objetivo de aperfeiçoar a utilização do conhecimento, a eficiência dos trabalhos, bem como a qualidade dos bens ou serviços prestados. De acordo com a PINTEC (IBGE, 2012), deve ser o resultado de decisões estratégicas tomadas pela gestão e constituir novidade para a companhia, o que não inclui, porém, as fusões ou aquisições, ainda que constituam uma novidade organizacional para ela (LOPES; BEUREN, 2016).

Inovações mercadológicas ou de marketing envolvem a "implementação de um novo método de marketing com mudanças significativas na aparência do produto ou em sua embalagem, no posicionamento do produto, em sua promoção ou na fixação de preços" (OECD, 2005, p. 59). As inovações mercadológicas estão voltadas para aspectos de comercialização, logística, design, maneira de embalar e estratégias inovadoras que possam proporcionar favorecimentos aos clientes (FLORIANI, 2009). Quando as organizações implantam esse tipo de inovação visam a obter maior volume de vendas, maior fatia de mercado, mudanças de posicionamento, melhoria da marca e/ou da reputação (CARVALHO; REIS; CAVALCANTE, 2011).

Estas quatro categorias de inovação podem ser implementadas em uma organização de forma individual ou conjunta. Independentemente da tipologia, a inovação tende a crescer proporcionalmente de acordo com as pressões advindas dos clientes e da concorrência; o aumento dela tende a desencadear melhor desempenho nas corporações. Nesse sentido, ressalta-se a importância do processo de inovação, não apenas para dar continuidade aos negócios, mas também para expandi-los ou até mesmo reinventá-los se for o caso; ele requer instrumentos gerenciais que possam prover as informações necessárias ao planejamento e acompanhamento da inovação nas empresas.

\subsection{Uso de instrumentos do Sistema de Controle Gerencial e gestão da inovação}

$\mathrm{Na}$ revisão da literatura identificaram-se alguns estudos que associaram controles gerenciais com gestão da inovação. Nesse sentido, no Quadro 1 apresentam-se inicialmente pesquisas internacionais, seguidas de nacionais, que de alguma forma possam contribuir na análise dos resultados deste trabalho, com ênfase nos autores, ano e periódico de publicação, além de resumir o objeto proposto, a metodologia e os principais resultados. 


\section{Quadro 1: Pesquisas anteriores que associaram controles gerenciais com gestão da inovação}

\begin{tabular}{|c|c|c|c|c|}
\hline Autores & Periódico & Objetivo & $\begin{array}{l}\text { Metodologia da } \\
\text { pesquisa }\end{array}$ & Resultados \\
\hline $\begin{array}{l}\text { Bisbe e Otley } \\
(2004)\end{array}$ & $\begin{array}{l}\text { Accounting, } \\
\text { Organizations } \\
\text { and Society }\end{array}$ & $\begin{array}{l}\text { Discriminar os dife- } \\
\text { rentes efeitos do uso } \\
\text { interativo do SCG na } \\
\text { inovação de produtos } \\
\text { e desempenho das } \\
\text { empresas }\end{array}$ & $\begin{array}{l}\text { Investigaram } 120 \text { em- } \\
\text { presas espanholas com } \\
\text { um volume de negó- } \\
\text { cios anual entre } € 18 \text { e } \\
180 \text { milhões e entre } 200 \\
\text { e } 2.000 \text { funcionários }\end{array}$ & $\begin{array}{l}\text { Não foi confirmado que o uso intera- } \\
\text { tivo do SCG contribui para a inovação } \\
\text { de produtos. Porém, nas empresas } \\
\text { com menor nível de inovação foi } \\
\text { verificado efeito positivo do uso inte- } \\
\text { rativo na inovação; por outro lado, em } \\
\text { empresas com alto nível de inovação } \\
\text { o efeito foi negativo }\end{array}$ \\
\hline $\begin{array}{l}\text { Bisbe e } \\
\text { Malagueño } \\
\text { (2009) }\end{array}$ & $\begin{array}{l}\text { European } \\
\text { Accounting } \\
\text { Review }\end{array}$ & $\begin{array}{l}\text { Verificar se fatores } \\
\text { organizacionais } \\
\text { sistemáticos levam } \\
\text { os gestores a fazerem } \\
\text { diferentes escolhas } \\
\text { em relação ao SGC } \\
\text { selecionado para o } \\
\text { uso interativo }\end{array}$ & $\begin{array}{l}\text { Pesquisaram } 57 \\
\text { empresas espanholas } \\
\text { de médio porte. Os } \\
\text { controles eram parte } \\
\text { da inovação mais do } \\
\text { que um dispositivo } \\
\text { externo para torná-lo } \\
\text { transparente }\end{array}$ & $\begin{array}{l}\text { A escolha do SGC específico relacio- } \\
\text { nado ao modelo de gestão da inova- } \\
\text { ção fornece em parte uma adequação } \\
\text { suplementar. Essa adequaçãa, entre- } \\
\text { tanto, não conduz a uma habilidade } \\
\text { melhorada; ela reforça a tendência já } \\
\text { existente da organização }\end{array}$ \\
\hline $\begin{array}{l}\text { Revellino e } \\
\text { Mouritsen } \\
\text { (2009) }\end{array}$ & $\begin{array}{l}\text { European } \\
\text { Accounting } \\
\text { Review }\end{array}$ & $\begin{array}{l}\text { Mostrar no estudo } \\
\text { como os controles } \\
\text { interferem e transfor- } \\
\text { mam a inovação }\end{array}$ & $\begin{array}{l}\text { Estudo de caso da } \\
\text { empresa de pedágios } \\
\text { italiana, a Telepass, } \\
\text { que ilustra a multipli- } \\
\text { cidade de controles em } \\
\text { inovação e o envolvi- } \\
\text { mento destes com o } \\
\text { desenvolvimento da } \\
\text { inovação }\end{array}$ & $\begin{array}{l}\text { Os resultados mostraram que a ino- } \\
\text { vação passa por diferentes processos, } \\
\text { exigindo também inovações adicio- } \\
\text { nais. O conjunto de controles incluiu } \\
\text { elementos de planejamento orçamen- } \\
\text { tário, visão estratégica, satisfação do } \\
\text { usuário, produtividade e metas de } \\
\text { realização altamente ousadas. Essa } \\
\text { multiplicidade de controles alterados } \\
\text { e adaptados à inovação ajuda a de- } \\
\text { senvolvê-la. Os controles são parte da } \\
\text { inovação e não apenas um dispositivo } \\
\text { externo para torná-la transparente }\end{array}$ \\
\hline $\begin{array}{l}\text { Oyadomary } \\
\text { et al. (2010) }\end{array}$ & $\begin{array}{l}\text { Revista Uni- } \\
\text { verso Contábil }\end{array}$ & $\begin{array}{l}\text { Verificar se existe } \\
\text { conflito entre o uso } \\
\text { do SCG e o processo } \\
\text { de inovação e identi- } \\
\text { ficar outras caracte- } \\
\text { rísticas do Sistema }\end{array}$ & $\begin{array}{l}\text { Pesquisaram três } \\
\text { empresas brasileiras } \\
\text { classificadas como } \\
\text { inovadoras na listagem } \\
\text { que compõem o Índice } \\
\text { Brasil de Inovação } \\
\text { desenvolvido pela } \\
\text { UNICAMP/UNIEMP/ } \\
\text { FAPESP em } 2007\end{array}$ & $\begin{array}{l}\text { Os resultados indicaram que tal } \\
\text { conflito não está presente nessas or- } \\
\text { ganizações, o que pode ser explicado } \\
\text { pelo fato de a inovação ser um valor } \\
\text { permanente nelas }\end{array}$ \\
\hline $\begin{array}{l}\text { Utzig e Beu- } \\
\text { ren (2015) }\end{array}$ & $\begin{array}{l}\text { Revista de } \\
\text { Adminis- } \\
\text { tração e } \\
\text { Inovação }\end{array}$ & $\begin{array}{l}\text { Identificar a relação } \\
\text { entre o nível do uso } \\
\text { interativo de instru- } \\
\text { mentos do SCG com } \\
\text { os modelos de gestão } \\
\text { da inovação propos- } \\
\text { tos por Roussel, Saad } \\
\text { e Erickson (1991) em } \\
\text { empresas industriais } \\
\text { brasileiras }\end{array}$ & $\begin{array}{l}\text { Investigaram } 28 \\
\text { empresas listadas } \\
\text { na revista "Exame } \\
\text { Melhores e Maiores", } \\
\text { edição } 2011\end{array}$ & $\begin{array}{l}\text { Os resultados mostraram predo- } \\
\text { minância do modelo de gestão de } \\
\text { inovação estratégico não especialista, } \\
\text { ou seja, aquele que não requer conhe- } \\
\text { cimentos altamente técnicos (BISBE; } \\
\text { MALAGUEÑO, 2009). Os autores } \\
\text { concluíram que o uso interativo de } \\
\text { instrumentos do SCG adequados ao } \\
\text { modelo de gestão de inovação se- } \\
\text { guido pela empresa pode influenciar } \\
\text { positivamente o nível de inovação }\end{array}$ \\
\hline
\end{tabular}

Fonte: Elaborado pelos autores. 
Bisbe e Otley (2004) objetivaram discriminar os diferentes efeitos do uso interativo do SCG na inovação de produtos e no desempenho de 120 empresas espanholas com um volume de negócios anual de entre $€ 18$ e 180 milhões e entre 200 e 2.000 funcionários. Os resultados da pesquisa não confirmaram que o uso interativo do SCG contribui para a inovação de produtos. Porém, nas empresas com menor nível de inovação foi verificado efeito positivo do uso interativo na inovação, por outro lado, em empresas com alto nível de inovação o efeito foi negativo. Na primeira situação, o uso interativo do SCG pode propiciar estímulos às iniciativas de inovação. Nas empresas altamente inovadoras, o alto uso interativo do Sistema parece provocar uma filtragem de iniciativas das ideias expostas, levando a uma redução da inovação. Também não constataram efeito indireto no desempenho, mas os resultados indicaram que quanto mais interativo for o SCG formal utilizado pelas empresas, maior será o efeito positivo da inovação dos produtos no desempenho delas.

Bisbe e Malagueño (2009) verificaram se fatores organizacionais sistemáticos levam os gestores a fazerem diferentes escolhas em relação ao SGC selecionado para o uso interativo em 57 empresas espanholas de médio porte. Além disso, examinaram a adequação do sistema selecionado em relação ao modo de gestão de inovação e se trazia benefícios aos resultados das inovações de produtos. Os resultados mostraram que a escolha do SGC específico relacionado ao modelo de gestão da inovação fornece em parte uma adequação suplementar. Essa adequação, entretanto, não conduz a uma habilidade melhorada, ela reforça a tendência já existente da organização; ou seja, empresas altamente inovadoras podem alcançar níveis mais elevados de inovação, ao passo que aquelas com baixo nível de inovação tendem a apresentar níveis ainda menores.

Revellino e Mouritsen (2009) averiguaram, por meio de um estudo de caso em uma empresa italiana de pedágio, como os controles interferem e transformam a inovação. Observaram que a inovação passa por diferentes processos, os quais necessitam de variados controles para mediar a inovação e seu ambiente. O levantamento propõe também que a inovação é mediada por diferentes tecnologias de gestão e que os controles fazem parte da inovação e funcionam como um dispositivo externo para torná-la transparente. O controle 
também deve ser estruturado em relação às características da inovação. Em vez de responder basicamente ao contexto estratégico e às incertezas em torno da inovação, os controles estão envolvidos mais em ensaios em torno de desafios específicos para o desenvolvimento da inovação.

Oyadomary et al. (2010) verificaram se há conflito entre o uso de SCG e o processo de inovação e buscaram identificar outras características do sistema em três empresas brasileiras, classificadas como inovadoras na listagem das que compõem o Índice Brasil de Inovação desenvolvido pela UNICAMP/UNIEMP/FAPESP, em 2007. Os resultados indicaram que tal conflito não está presente nessas organizações, o que pode ser explicado pelo fato de a inovação ser um valor permanente nelas. Além disso, também evidenciaram que são utilizados por essas empresas artefatos de controle gerencial classificados como tradicionais e que estes não inibem a inovação, ao contrário, a estimulam.

Utzig e Beuren (2015) buscaram identificar a relação entre o nível do uso interativo de instrumentos do Sistema de Controle Gerencial com os modelos de gestão da inovação propostos por Roussel, Saad e Erickson (1991) em empresas industriais brasileiras. A pesquisa analisou 28 empresas listadas na "Exame Melhores e Maiores", edição 2011, e os resultados mostraram predominância do modelo de gestão de inovação estratégico não especialista, que não requer conhecimentos altamente técnicos (BISBE; MALAGUEÑO, 2009). Concluíram que o uso interativo de instrumentos do SCG adequados ao modelo de gestão de inovação seguido pela empresa pode influenciar positivamente o nível de inovação.

Ressalta-se também a preocupação do governo brasileiro com a criação de programas de incentivos fiscais à inovação, por meio da Lei n. 11.196, de 21 de novembro de 2005 (BRASIL, 2005), mais conhecida como Lei do Bem, para auxiliar no desenvolvimento de processos inovadores nas organizações que possibilitem retorno para a sociedade (LOPES; BEUREN, 2016). De acordo com esses autores, essa lei visa a estimular as empresas a promoverem internamente atividades de pesquisa tecnológica e desenvolvimento de inovação tecnológica, quer na concepção de novos produtos, quer na agregação de novas funcionalidades ou características ao produto ou 
processo, o que é um cenário propício para as corporações inovarem e se tornarem competitivas estrategicamente perante os concorrentes.

Depreende-se do que até aqui exposto que os controles gerenciais contribuem para o desenvolvimento de estratégias competitivas, dentre elas as de inovação nas empresas. De acordo com Simons (1990), são parte de um sistema social dinâmico, que influencia diretamente o processo de inovação de forma positiva. Davila (2000) constatou uma relação positiva entre os sistemas de controle gerencial e o desempenho de desenvolvimento de produtos nas empresas pesquisadas. Verificou também que há relação positiva de custo e design dos produtos com o desempenho. Davila e Foster (2005) observaram em sua pesquisa que a maior valorização é encontrada naquelas empresas que alinham suas escolhas de sistemas de controle gerencial com o seu posicionamento estratégico em particular, os sistemas que implementam a estratégia são percebidos mais importantes e valiosos do que outros.

\section{Procedimentos metodológicos}

Nesta pesquisa descritiva com abordagem quantitativa do problema adotaram-se procedimentos técnicos de levantamento, por meio do envio de um questionário aos gestores de empresas. Esse tipo de pesquisa justifica-se pelo fato de se descreverem as características das variáveis relacionadas aos instrumentos de controle gerencial e à inovação das empresas. Cooper e Schindler (2003) expõem que estudos dessa natureza visam a descrever fenômenos ou características associadas com a população-alvo.

A pesquisa quantitativa foi utilizada com o propósito de analisar a intensidade das variáveis (RAUPP; BEUREN, 2009). No que concerne à pesquisa de levantamento ou survey, essa classificação decorre da aplicação de um questionário à população preestabelecida. Em ciências sociais esse instrumento é comumente utilizado quando busca-se conhecer o comportamento de determinada população (GIL, 2002). Martins e Theóphilo (2007) mencionam que a pesquisa do tipo levantamento é apropriada para investigações que visam a conhecer o comportamento de indivíduos. 


\subsection{População e amostra}

A população da pesquisa compreende "o conjunto de elementos que possuem determinadas características" (RICHARDSON, 1999, p. 103). Neste trabalho ela é composta por empresas estabelecidas em incubadoras localizadas na região sul do Brasil. A opção pelas empresas incubadas justifica-se inicialmente pelo seu perfil: têm rápida ascensão e, por conseguinte, o nível de risco a que estão expostas é maior do que as demais, já que lhes é exigida uma adequação às mudanças de mercado mais rapidamente. Além disso, essas ações podem se refletir nos instrumentos gerenciais, em especial, pelo fato de apresentarem um nível elevado de atividade inovativa.

A amostra do estudo de levantamento foi composta pelos 12 participantes da pesquisa, portanto uma amostra por acessibilidade. Os sujeitos respondentes do questionário selecionados são os gestores ou responsáveis pelas informações gerenciais da organização relacionadas à Pesquisa, Desenvolvimento e Inovação. $\mathrm{O}$ contato com esse grupo de empresas ocorreu via correio eletrônico, pelo qual foi enviada uma carta de apresentação com a exposição dos objetivos da pesquisa, além de informar o link do instrumento a ser utilizado.

\subsection{Construto da pesquisa}

No Quadro 2 apresenta-se o construto da pesquisa, com ênfase nas variáveis, subvariáveis e referências que basearam as escolhas dos elementos do construto.

\subsection{Instrumento de pesquisa}

$\mathrm{O}$ instrumento de pesquisa foi desenvolvido com foco no objetivo do estudo, subsidiado pela revisão de literatura. O questionário compõe-se de dois blocos: o primeiro, constituído com base no trabalho de Davila e Foster (2005), aborda os instrumentos de controle gerencial e restringe-se ao planejamento financeiro, planejamento estratégico e planejamento de recursos humanos; e o segundo versa sobre o nível da inovação de produtos e processos das empresas e foi constituído com base nos estudos de Bisbe e Otley (2004), Soly et al. (2014), Lopes e Beuren (2016). 
Quadro 2: Construto da pesquisa

\begin{tabular}{|c|c|c|}
\hline Variáveis & Subvariáveis & Referências \\
\hline \multirow{2}{*}{$\begin{array}{l}\text { Planejamento } \\
\text { Financeiro }\end{array}$} & Projeções de fluxo de caixa & \multirow{14}{*}{\begin{tabular}{|l} 
\\
\\
Davila e Foster \\
(2005)
\end{tabular}} \\
\hline & Orçamento operacional & \\
\hline \multirow{5}{*}{$\begin{array}{l}\text { Planejamento } \\
\text { Estratégico }\end{array}$} & $\begin{array}{l}\text { Definiçãa de metas estratégicas } \\
\text { (não financeiras) }\end{array}$ & \\
\hline & $\begin{array}{l}\text { Plano de desenvolvimento de } \\
\text { clientes (plano para desenvol- } \\
\text { ver o mercado) }\end{array}$ & \\
\hline & $\begin{array}{l}\text { Plano de desenvolvimento do } \\
\text { capital humano }\end{array}$ & \\
\hline & $\begin{array}{l}\text { Plano de portfólio de produtos/ } \\
\text { plano sobre produtos futuros }\end{array}$ & \\
\hline & Orçamento de investimento & \\
\hline \multirow{7}{*}{$\begin{array}{l}\text { Planejamento } \\
\text { de Recursos } \\
\text { Humanos }\end{array}$} & Valores fundamentais & \\
\hline & Declaração da missão & \\
\hline & Organograma & \\
\hline & Códigos de conduta & \\
\hline & $\begin{array}{l}\text { Descrições das funções por } \\
\text { escrito }\end{array}$ & \\
\hline & $\begin{array}{l}\text { Programa de orientação de } \\
\text { novos funcionários }\end{array}$ & \\
\hline & Boletim de notícias da empresa & \\
\hline \multirow{4}{*}{$\begin{array}{l}\text { Inovação de } \\
\text { produto }\end{array}$} & Lançamento de novos produtos & \multirow{7}{*}{$\begin{array}{l}\text { Bisbe e Otley (2004), } \\
\text { Soly et al. (2014), Lo- } \\
\text { pes e Beuren (2016) }\end{array}$} \\
\hline & $\begin{array}{l}\text { Modificações em produtos já } \\
\text { existentes }\end{array}$ & \\
\hline & $\begin{array}{l}\text { Liderança de mercado no lan- } \\
\text { çamento de novos produtos }\end{array}$ & \\
\hline & $\begin{array}{l}\text { A porcentagem de novos pro- } \\
\text { dutos no portfólio }\end{array}$ & \\
\hline \multirow{3}{*}{$\begin{array}{l}\text { Inovação de } \\
\text { processo }\end{array}$} & $\begin{array}{l}\text { Implementação de novos pro- } \\
\text { cessos }\end{array}$ & \\
\hline & $\begin{array}{l}\text { Modificações em processos já } \\
\text { existentes }\end{array}$ & \\
\hline & $\begin{array}{l}\text { Implementação de melhorias } \\
\text { incrementais nos processos }\end{array}$ & \\
\hline
\end{tabular}

Fonte: Elaborado pelos autores. 
O primeiro bloco teve como propósito mapear a intensidade de uso de instrumentos gerenciais nas empresas, de forma geral, e tratar da inovação. Nesse sentido, o respondente foi solicitado a atribuir um valor na escala Likert de 1 a 7 , em que: 1 = não existe na empresa; 2 = está em fase de implementação; 3 = uso incipiente em alguns pontos; 4 = uso incipiente de modo geral; 5 = usado em alguns pontos; 6 = usado moderadamente de modo geral; e 7 = usado muito de modo geral.

Nesse bloco de questões, foram expostos dois controles de planejamento financeiro (projeções de fluxo de caixa; e orçamento operacional), cinco de planejamento estratégico (definição de metas estratégicas - não financeiras; plano de desenvolvimento de clientes - plano para desenvolver o mercado; plano de desenvolvimento do capital humano; plano de portfólio de produtos/plano sobre produtos futuros; e orçamento de investimento) e sete controles de planejamento de recursos humanos (valores fundamentais; declaração da missão; organograma; códigos de conduta; descrições das funções por escrito; programa de orientação de novos funcionários; e boletim de notícias da empresa).

O segundo bloco buscou averiguar o nível de inovação de produtos e processos das empresas objeto de estudo. Assim, o respondente foi solicitado a atribuir um valor na escala Likert de 1 a 7, em que: 1 = menos que os concorrentes; e 7 = mais que os concorrentes; ou ainda as alternativas NA = não se aplica; ou NS = não sei dizer. Esse bloco contou com sete questões, entre as quais quatro relacionadas à inovação de produtos, e três à inovação de processos.

A escala Likert de sete pontos utilizada, conforme Cooper e Schindler (2003), aponta que esse tipo de escala psicométrica é usado habitualmente em questionários, uma vez que tem a capacidade de abranger maior proximidade entre os respondentes de uma distribuição normal das respostas. Ressalta-se que a forma de mensuração das variáveis pertencentes ao nível de inovação de produtos e inovação de processos foi realizada com base no estudo de Bisbe e Otley (2004) e que a forma de mensuração dos instrumentos de controle gerencial foi baseada na tipologia de uso construída por Simons (1995b). Destaca-se também que o questionário elaborado foi submetido à avaliação de três pesquisadores, que propuseram 
mudanças na redação com vistas a conferir-lhe maior possibilidade de entendimento.

\subsection{Procedimentos de coleta e análise de dados}

$\mathrm{O}$ instrumento de pesquisa foi configurado e enviado pelo Google Docs, uma plataforma on-line que permite fazer o gerenciamento de todo o processo, desde criar os formulários, gerenciar as respostas e enviar para a população-alvo. A coleta de dados foi feita nos meses de junho e julho de 2016. O link do questionário foi enviado diversas vezes para os gestores ou responsáveis pelas informações gerenciais das empresas incubadas, a fim de obter uma quantidade de respostas que permitisse a aplicação de técnicas de estatísticas descritivas.

Os dados obtidos foram organizados no Microsoft Excel® e posteriormente serviram como base para o tratamento de dados. Inicialmente realizou-se a caracterização dos respondentes, utilizando-se de estatística descritiva. No que concerne aos instrumentos de controle gerencial e nível de inovação de produtos e processos das empresas, foi feito o cálculo da média, máximo, mínimo, desvio-padrão e entropia informacional das variáveis.

Santos, Rocha e Hein (2014, p. 88) afirmam, pautados em Borges (1999), que "a entropia constitui a essência da mecânica estatística e também exerce papel central na teoria da informação. A sua interpretação física beneficia outras áreas do conhecimento, tais como filosofia, economia e computação". O cálculo da entropia informacional foi realizado com base na proposição de Zeleny (1982), conforme demonstrado por Moura e Beuren (2011).

\section{DESCRIÇÃo E ANÁliSE DOS RESUlTAdoS}

\subsection{Perfil dos respondentes e dados demográficos das em- presas incubadas}

Pelos dados coletados e tabulados, foi possível constatar que oito gestores são do gênero masculino e quatro do feminino. Desse grupo, cinco possuem acima de 20 anos, três estão na faixa dos 30 a 40 anos, dois gestores possuem mais de 40 anos e dois possuem acima de 50 anos. Infere-se que são empresas de modo geral geren- 
ciadas por jovens, uma vez que mais de $60 \%$ do grupo analisado pertence à faixa etária de 20 a 37 anos. A idade mínima encontrada foi 22, e a máxima, 54 .

No que concerne à escolaridade, com exceção de um respondente, todos possuem ensino superior. Três dos respondentes possuem curso de especialização, quatro de mestrado e quatro de graduação. As funções exercidas por esse grupo são sócio/diretor (2), diretor (2), gerente (2), CEO (1), administradores (2), profissional de Controladoria (1), engenheiro (1) e assistente administrativo (1). O tempo que exercem essa função está entre 1 a 8 meses (3), 1 ano (3), 2 anos (1), 3 anos (3), 10 anos (1) e 14 anos (1).

Quanto ao setor de atuação, o grupo analisado é plural: compõe-se de quatro empresas de TIC (software e segurança eletrônica e telecomunicações), 2 de utilidade pública (energia para o campo e recursos hídricos), 2 de indústria (alimentos e nanotecnologia), 1 de metal mecânica (bombeamento de água e geração de energia), 1 de saúde (laboratório de genética e biologia molecular), 1 de decoração (vendas) e 1 de serviços (consultoria). Quanto ao tempo de constituição, a amostra compõe-se de companhias novas, uma vez que duas ainda não completaram 1 ano de atividade, cinco (1 a 4 anos), duas (5 a 8 anos), duas (12 a 14 anos) e uma empresa está atuando há 36 anos no mercado.

Para mapear a intensidade de uso de instrumentos de controle gerencial nas empresas, de forma geral, e para tratar da inovação, de forma específica, apresenta-se a Tabela 1.

Tabela 1: Mapeamento da intensidade de uso de instrumentos de controle gerencial

\begin{tabular}{l|l|l|l|l|l|l|l}
\hline $\begin{array}{l}\text { Instrumentos de } \\
\text { controle gerencial }\end{array}$ & $\begin{array}{l}\text { Mé- } \\
\text { dia }\end{array}$ & Moda & Máx. & Mín. & DP & $\begin{array}{l}\text { En- } \\
\text { tropia }\end{array}$ & $\begin{array}{l}\text { Peso da } \\
\text { informação }\end{array}$ \\
\hline $\begin{array}{l}\text { Planejamento } \\
\text { Financeiro }\end{array}$ & \multicolumn{7}{|l|}{} \\
\hline $\begin{array}{l}\text { Projeções de } \\
\text { fluxo de caixa }\end{array}$ & 4,91 & 6 & 7 & 2 & 1,89 & 0,9672 & 0,039422487 \\
\hline $\begin{array}{l}\text { Orçamento } \\
\text { operacional }\end{array}$ & 4,91 & 6 & 7 & 1 & 1,71 & 0,9710 & 0,034896789 \\
\hline
\end{tabular}




\begin{tabular}{|c|c|c|c|c|c|c|c|}
\hline $\begin{array}{l}\text { Planejamento } \\
\text { Estratégico }\end{array}$ & & & & & & & \\
\hline $\begin{array}{l}\text { Definição de me- } \\
\text { tas estratégicas } \\
\text { (não financeiras) }\end{array}$ & 5,75 & 7 & 7 & 3 & 1,16 & 0,9911 & 0,010699872 \\
\hline $\begin{array}{l}\text { Plano de desen- } \\
\text { volvimento de } \\
\text { clientes (plano } \\
\text { para desenvolver } \\
\text { o mercado) }\end{array}$ & 5,00 & 4 & 7 & 3 & 1,41 & 0,9841 & 0,019064995 \\
\hline $\begin{array}{l}\text { Plano de desen- } \\
\text { volvimento do } \\
\text { capital humano }\end{array}$ & 4,16 & 2 & 7 & 1 & 1,95 & 0,9515 & 0,058294027 \\
\hline $\begin{array}{l}\text { Plano de portfó- } \\
\text { lio de produtos/ } \\
\text { plano sobre pro- } \\
\text { dutos futuros }\end{array}$ & 5,50 & 6 & 7 & 3 & 1,12 & 0,9911 & 0,010730383 \\
\hline $\begin{array}{l}\text { Orçamento de } \\
\text { investimento }\end{array}$ & 4,16 & 3 & 7 & 1 & 2,03 & 0,9492 & 0,061017852 \\
\hline $\begin{array}{l}\text { Planejamento de } \\
\text { Recursos Huma- } \\
\text { nos }\end{array}$ & & & & & & & \\
\hline $\begin{array}{l}\text { Valores funda- } \\
\text { mentais }\end{array}$ & 4,00 & 5 & 7 & 1 & 2,2 & 0,9344 & 0,078849582 \\
\hline $\begin{array}{l}\text { Declaração da } \\
\text { missão }\end{array}$ & 4,08 & 2 & 7 & 1 & 2,22 & 0,9375 & 0,075103908 \\
\hline Organograma & 3,75 & 7 & 7 & 1 & 2,38 & 0,9190 & 0,097268813 \\
\hline $\begin{array}{l}\text { Códigos de con- } \\
\text { duta }\end{array}$ & 3,25 & 1 & 7 & 1 & 2,42 & 0,8927 & 0,128915531 \\
\hline $\begin{array}{l}\text { Descrições das } \\
\text { funções por } \\
\text { escrito }\end{array}$ & 2,91 & 1 & 7 & 1 & 2,14 & 0,8983 & 0,122196876 \\
\hline $\begin{array}{l}\text { Programa de } \\
\text { orientação de no- } \\
\text { vos funcionários }\end{array}$ & 4,16 & 1 & 7 & 1 & 2,64 & 0,9069 & 0,111807903 \\
\hline $\begin{array}{l}\text { Boletim de notí- } \\
\text { cias da empresa }\end{array}$ & 3,25 & 1 & 7 & 1 & 2,59 & 0,8737 & 0,151730983 \\
\hline
\end{tabular}

Fonte: Dados da pesquisa. 
Observam-se na Tabela 1 os resultados tabulados das 12 empresas participantes da pesquisa. A frequência média de ambos os controles de planejamento financeiro é idêntica; o desvio-padrão apresentou-se inferior à média, indicando homogeneidade entre as respostas. No Planejamento Estratégico, a definição de metas estratégicas (não financeiras) mostrou-se com maior frequência. Nesse grupo, orçamento de investimento e plano de desenvolvimento do capital humano tiveram as mesmas médias e as menores do grupo. Na categoria Planejamento de Recursos Humanos, a que apresentou maior frequência foi valores fundamentais, e a menor média foi em descrições das funções por escrito.

Os controles de Planejamento de Recursos Humanos voltados para códigos de conduta, descrições das funções por escrito, programa de orientação de novos funcionários e boletim de notícias da empresa não existem nas empresas participantes, o que pode ser um reflexo do tempo de constituição delas. Esses controles também foram os que apresentaram maior peso da informação, ou seja, maior dispersão entre as respostas, o que demanda atenção para possíveis inferências e também dos gestores dessas empresas, especialmente pelo fato de caracterizarem controles de gestão típicos de estágios mais avançados do crescimento das organizações.

Quanto ao peso da informação calculado para os demais itens, como os relacionados ao Planejamento Financeiro e ao Planejamento Estratégico, todos apresentaram-se com poucas dispersões informacionais, ou seja, há uma atenção equilibrada quanto ao uso desses controles gerenciais nas empresas pesquisadas. Esse achado reforça-se com o desvio-padrão, que é menor que a média em todos os demais itens investigados.

O Planejamento Financeiro, que neste estudo abarca as projeções de fluxo de caixa e orçamento operacional, compreende práticas decorrentes do Planejamento Estratégico, que visam a direcionar o comportamento do gestor dentro da organização (HORNGREN et al., 2009). Quando a temática é o processo de inovação e o alinhamento com o orçamento, existe uma necessidade de ter esse instrumento gerencial dentro da organização: em um primeiro momento para garantir o controle dos recursos destinados às atividades prioritárias dela; e em um segundo momento, com vistas a observar como está 
ocorrendo o comprometimento das pessoas com relação às metas e processos estabelecidos.

O orçamento operacional é relevante para a empresa, pois tem a capacidade de envolvê-la em uma linguagem única, que em muitos casos culmina para o objetivo-fim dela (OTLEY, 1999; ANTHONY; GOVINDARAJAN, 2008). Nesse aspecto, em se tratando de inovação, fazer uso de tal instrumento pode maximizar a atividade operacional e conceder maior liberdade de criação aos envolvidos, pelo fato de conhecerem os limites orçamentários e os recursos que destinados para a consecução dessa atividade.

\subsection{Nível de inovação de produtos e inovação de processos}

Na Tabela 2 são apresentadas a estatística descritiva e a entropia informacional do nível de inovação de produtos e inovação de processos das incubadas pesquisadas.

Observa-se na Tabela 2 o cenário relativo ao nível de inovação nas empresas pesquisadas. Quanto à inovação de produtos, elas têm lançado novos produtos com frequência maior do que os concorrentes; a situação é semelhante no que se refere às modificações em produtos já existentes. As companhias analisadas apresentam média frequência quanto aos novos produtos no portfólio e no que tange à liderança de mercado. Na inovação de processo, não existe uma diferença significativa quanto à frequência com que as atividades são realizadas dentro da organização. O desvio-padrão de todos esses itens indica que não há elevado grau de divergência, uma vez que todos apresentaram-se menores que a média.

Beck e Beuren (2014, p. 3) afirmam que a inovação "remete ao entendimento de algo novo, como uma nova ideia, um novo método ou dispositivo, ou ainda como um processo de introdução de algo novo". Esse escopo é observado de forma ampla nas empresas respondentes. Recorrendo-se às tipologias de inovação de Schumpeter (1998), enquadram-se as práticas de: i) introduzir um novo bem para o mercado; e ii) introduzir um novo método de produção. Tanto a inovação de produtos como a de processos fazem-se presentes nas empresas conforme apontado pelos respondentes. 
Tabela 2: Nível de inovação de produtos e inovação de processos

\begin{tabular}{|c|c|c|c|c|c|c|c|}
\hline Inovação de & $\begin{array}{l}\text { Mé- } \\
\text { dia }\end{array}$ & Moda & Máx. & Mín. & DP & Entropia & $\begin{array}{l}\text { Peso da } \\
\text { informa- } \\
\text { ção }\end{array}$ \\
\hline \multicolumn{8}{|l|}{ Produto } \\
\hline $\begin{array}{l}\text { Lançamento } \\
\text { de novos } \\
\text { produtos }\end{array}$ & 5,75 & 6 & 7 & 3 & 1,163687 & 0,990897 & 0,07603596 \\
\hline $\begin{array}{l}\text { Modificações } \\
\text { em produtos } \\
\text { já existentes }\end{array}$ & 5,50 & 6 & 7 & 3 & 1,322876 & 0,987280 & 0,10624679 \\
\hline $\begin{array}{l}\text { Liderança de } \\
\text { mercado no } \\
\text { lançamento } \\
\text { de novos } \\
\text { produtos }\end{array}$ & 4,25 & 4 & 7 & 1 & 1,963203 & 0,950877 & 0,41029658 \\
\hline $\begin{array}{l}\text { Porcentagem } \\
\text { de novos } \\
\text { produtos no } \\
\text { portfólio }\end{array}$ & 4,58 & 5 & 6 & 1 & 1,320248 & 0,978871 & 0,17647704 \\
\hline \multicolumn{8}{|l|}{ Processo } \\
\hline $\begin{array}{l}\text { Implementa- } \\
\text { ção de novos } \\
\text { processos }\end{array}$ & 5,66 & 7 & 7 & 3 & 1,312335 & 0,988352 & 0,09728971 \\
\hline $\begin{array}{l}\text { Modifica- } \\
\text { ções em } \\
\text { processos já } \\
\text { existentes }\end{array}$ & 5,58 & 6 & 7 & 4 & 1,114924 & 0,991768 & 0,06875992 \\
\hline $\begin{array}{l}\text { Implemen- } \\
\text { tação de } \\
\text { melhorias } \\
\text { incrementais } \\
\text { nos proces- } \\
\text { sos }\end{array}$ & 5,66 & 5 & 7 & 4 & 1,105542 & 0,992231 & 0,06489401 \\
\hline
\end{tabular}

Fonte: Dados da pesquisa. 
Na entropia informacional calculada, observa-se na Tabela 1 que a liderança de mercado no lançamento de novos produtos obteve o maior peso da informação. Isso indica que nesse quesito houve maior dispersão nas respostas, portanto trata-se de um aspecto que deve demandar maior atenção. Quanto à inovação de processo, o peso da informação apresentou-se baixo e bastante próximo nas três assertivas investigadas.

Inovar é um risco e demanda atenção por parte dos gestores. Tornar-se um líder de mercado em relação aos concorrentes é uma meta relativamente desafiadora, e se considerado o tempo de constituição das empresas, o cenário visualizado nesta pesquisa se justifica. Outro aspecto que está sustentado pelo tempo de constituição é a semelhança das médias na inovação de processo: as empresas em fase inicial do seu ciclo de vida devem buscar alternativas para melhor realizar seus processos, na busca de reduzir custos, aperfeiçoar processos e ganhar vantagem competitiva.

As implicações que esses resultados evidenciam é que as menores dispersões estão relacionadas à inovação de processo, lançamento de novos produtos e modificações em produtos já existentes. Por sua vez, a maior dispersão está na busca de as empresas tornarem-se líderes de mercado no lançamento de novos produtos; ou seja, por serem novas acabam focando em metas voltadas para o suprimento das suas necessidades iniciais. Infere-se, pelos números apresentados, o alinhamento do uso de instrumentos gerenciais com o grau de inovação de produtos e processos nas empresas pesquisadas.

\section{Conclusões}

Este estudo objetivou verificar o alinhamento da intensidade de uso de instrumentos do Sistema de Controle Gerencial com o nível da inovação de produtos e processos. Assim, pesquisa descritiva com abordagem quantitativa foi feita a partir de um levantamento com gestores de empresas incubadas. No mapeamento da intensidade de uso dos instrumentos de controle gerencial é notável a preocupação dos gestores com o planejamento estratégico, com destaque para definição de metas estratégicas (não financeiras) e plano de portfólio de produtos/plano sobre produtos futuros. 
No entanto, o uso dos instrumentos do planejamento financeiro também obteve indicações de uso com valores altos da escala. Portanto, as empresas analisadas acabam por vezes utilizando os instrumentos apontados de forma equitativa para a consecução dos objetivos. Por outro lado, pelo fato de se estarem analisando empresas com pouca maturidade, no processo de mudança e continuidade recebem pouca atenção dos gestores os aspectos relativos aos recursos humanos, o que já era esperado constatar. Como o foco são empresas incubadas, o planejamento quanto aos recursos humanos acaba por vezes acontecendo de modo informal, o que é característico nesse contexto.

Os resultados mostram ainda que as empresas pesquisadas apresentam um nível mais elevado no lançamento de novos produtos para o mercado e no aperfeiçoamento daqueles já existentes, no que tange à inovação de produtos, cujas médias estão muito próximas das assertivas relativas à inovação de processos. Esse cenário pode decorrer do tempo de fundação delas, uma vez que, quando uma companhia está iniciando suas atividades - mesmo naquelas com alto potencial de crescimento e inovação -, a preocupação primeira é na geração de receita, ou seja, vai direcionar esforços para a continuidade de suas operações e, consequentemente, crescer.

$\mathrm{Na}$ assimetria da informação calculada, o maior peso observado está na liderança de mercado no lançamento de novos produtos, um instrumento relativo ao grau de inovação de produtos, assim como percebido no planejamento de recursos humanos, embora em menor escala. A maior dispersão nas respostas para essas assertivas decorre do fato de que essas empresas se encontram nas fases iniciais de incubação, com foco nas prioridades de sobrevivência. Dessa forma, conclui-se que há evidências de alinhamento da intensidade de uso dos instrumentos de controle gerencial com o nível de inovação de produtos e de inovação de processos. Tal alinhamento com os propósitos da organização tende a trazer resultados positivos, que podem desembocar em crescimento do faturamento, contratação de pessoal, aumento dos processos inovadores e alcance dos objetivos e metas organizacionais.

As contribuições teóricas para este estudo estão em fornecer um novo cenário para a Contabilidade Gerencial, pois a partir deste pe- 
queno insight - e com parcimônia - é possível afirmar que para esse grupo de empresas há evidências de alinhamento da intensidade de uso de instrumentos de controle gerencial com o nível de inovação. É possível inferir que os instrumentos do SCG e a inovação são dois aspectos organizacionais que podem conduzir as corporações a modificações no seu escopo. Além disso, destaca-se que no caso de uma tendência perceptível do nível de inovação, à medida que o foco das atividades organizacionais ocorre, este também pode se refletir nos instrumentos de controle gerencial, uma perspectiva bidirecional a ser investigada em futuras pesquisas.

Como as constatações do estudo são oriundas de um grupo pequeno de empresas, reconhece-se que pode ser uma limitação para generalizações. Por outro lado, esse cenário instiga a realização de novos trabalhos, avançando no que concerne à quantidade de instrumentos considerados, que também podem colaborar com o processo de inovação na empresa. Outras formas de inovação igualmente podem abrir caminhos para novas contribuições. Sugere-se ainda investigar como ocorre esse processo de mudança organizacional e como os responsáveis pela Pesquisa e Desenvolvimento alinham-se aos recursos orçamentários com vistas a cumprir as metas determinadas e manter a continuidade do negócio.

\section{REFERÊNCIAS}

ANTHONY, R. N.; GOVINDARAJAN, V. Sistemas de controle gerencial. 12. ed. São Paulo: McGraw-Hill, 2008.

ATTIE, W. Auditoria: conceito e aplicações. 3. ed. São Paulo: Atlas, 1998.

BECK, F.; BEUREN, I. M. Interfaces da folga organizacional como inovação: um estudo em empresa têxtil. In: CONGRESSO ANPCONT, 8., 2014, Rio de Janeiro. Anais... São Paulo: ANPCONT, 2014.

BELTRAMI, L. C.; GOMES, S. M.; ARAÚJO, D. M. Sistemas de controle gerencial e desempenho corporativo: um estudo empírico em instituições de ensino superior. In: EnANPAD, 37. 2013, Rio de Janeiro. Anais eletrônicos... Disponível em: <http://www.anpad.org.br/admin/ pdf/2013_EnANPAD_CON2158.pdf>. Acesso em: 19 dez. 2015.

BERRY, A. J.; BROADBENT, J.; OTLEY, D. Management control: theories, issues and performance. 2. ed. Basingstoke: Palgrave Macmillan, 2005.

BEUREN, I. M.; ORO, I. M. Relação entre estratégia de diferenciação e inovação, e sistemas de controle gerencial. Revista de Administração Contemporânea, Rio de Janeiro, v. 18, n. 3, p. 285-310, 2014. 
BISBE, J.; MALAGUEÑO, R. The choice of interactive control systems under different innovation management modes. European Accounting Review, Brussels, v. 18, n. 2, p. 371-405, 2009.

BISBE, J.; OTLEY, D. The effects of the interactive use of management control systems on product innovation. Accounting, Organizations and Society, Clifton, UK, v. 29, n. 8. p. 709-737, 2004.

BRASIL. Lei n. 11.196, de 21 de novembro de 2005. Diário Oficial da União, Poder Legislativo, Brasília, DF, 22 nov. 2005. Disponível em: <http://www.planalto.gov.br/ccivil_03/_ato20042006/2005/lei/111196.htm>. Acesso em: 26 jul. 2016.

BRASIL. Ministério da Ciência, Tecnologia e Inovação (MCTI). Relatório anual da utilização

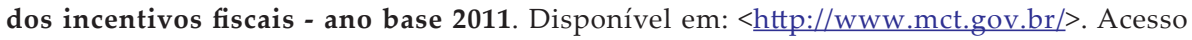
em: 5 ago. 2016.

CARVALHO, H. C.; REIS, D. R.; CAVALCANTE, M. B. Gestão da inovação. Curitiba: Aymará, Série UTFinova, 2011.

COOPER, D. R.; SCHINDLER, P. S. Métodos de pesquisa em administração. 7. ed. Porto Alegre: Bookman, 2003.

CRUZ, A. P. C.; FREZATTI, F.; BIDO, D. S. Estilo de liderança, controle gerencial e inovação: papel das alavancas de controle. Revista de Administração Contemporânea, Rio de Janeiro, v. 19, n. 6, p. 772-794, 2015.

D'AVILA, M. Z.; OLIVEIRA, M. A. M. Conceitos e técnicas de controles internos de organizações. São Paulo: Nobel, 2002.

DAVILA, A.; FOSTER, G. Management accounting systems adoption decisions: evidence and performance implications from early-stage/startup companies. The Accounting Review, Flórida, v. 80, n. 4, p. 1039-1068, 2005.

DAVILA, T. An empirical study on the drivers of management control systems' design in new product development. Accounting, Organization and Society, Clifton, UK, v. 25, n. 4-5, p. 383-409, 2000.

DOUGHERTY, D. Organizando para a inovação. In: CALDAS, S, M.; FACHIN, R.; FISCHER, T. (Org.). Handbook de estudos organizacionais: ação e análise organizacionais. São Paulo: Atlas, 2004. Vol. 3. p. 337-360.

DRUCKER, P. Inovação e espírito empreendedor: prática e princípios. São Paulo: Pioneira, 1999.

FLORIANI, R. Identificação de inovações e seus reflexos nos índices de rentabilidade de empresas brasileiras de capital aberto. 180 f. Dissertação (Mestrado em Administração) Universidade Regional de Blumenau, Blumenau, 2009.

FREEMAN, C. The national system of innovation in historical perspective. Revista Brasileira de Inovação, São Paulo, v. 3, n. 1, p. 15-34, 2004.

FREZATTI, F. et al. Instrumentos de controle gerencial e gestão da inovação: evidências empíricas brasileiras. In: Congresso ANPCONT, 6., 2012, Florianópolis. Anais... São Paulo: ANPCONT, 2012. 
GIL, A. C. Como elaborar projetos de pesquisa. 4. ed. São Paulo: Atlas, 2002.

HORNGREN, C. T. et al. Cost accounting: A managerial emphasis. 13. ed. New Jersey: Pearson Prentice Hall, 2009.

IBGE - INSTITUTO BRASILEIRO DE GEOGRAFIA ESTATISTICA. Pesquisa de Inovação (PINTEC). 2012. Disponível em: <www.ibge.gov.br $>$. Acesso em: 09 jan. 2015.

LOPES, I. F.; BEUREN, I. M. Evidenciação da inovação no Relatório da Administração: uma análise na perspectiva da Lei do Bem (Lei n. 11.196/2005). Perspectivas em Gestão \& Conhecimento, João Pessoa, v. 6, n. 1, p. 109-127, 2016.

LOPES, I. F.; BEUREN, I. M.; DAMETTO, I. R. B. Evidenciação da aplicação de recursos em Pesquisa, Desenvolvimento \& Inovação e da redução de carga tributária por empresas listadas na BM\&FBovespa. In: CONGRESSO UFSC DE CONTROLADORIA E FINANÇAS, 6., CONGRESSO UFSC DE INICIAÇÃO CIENTÍFICA, 6., E CONGRESSO IBEROAMERICANO DE CONTABILIDAD E GESTIÓN, 9., 2015, Florianópolis. Anais... Florianópolis: UFSC, 2015.

MARTINS, G. A.; THEÓPHILO, C. R. Metodologia da investigação científica para ciências sociais aplicadas. São Paulo: Atlas, 2007.

MENDONÇA. M. Fundamentos do controle. 2011. Disponível em: <http://www2.unifap.br/ mariomendonca/files/2011/05/FUNDAMENTOS-DO-CONTROLE.pdf > . Acesso em: 19 abr. 2016.

MERCHANT, K. A.; VAN DER STEDE, W. A. Management control systems: performance measurement, evaluation and incentives. 2. ed. Essex: Prentice Hall, 2007.

MOURA, G. D.; BEUREN, I. M. Conselho de Administração das empresas de Governança Corporativa listadas na BM\&FBovespa: análise à luz da entropia da informação da atuação independente. Revista de Ciências da Administração, Florianópolis, v. 13, n. 29, p. 11-37, 2011.

NISIYAMA, E. K.; OYADOMARI, J. C. T. Sistemas de controle gerencial e o processo de inovação. Revista de Administração e Inovação, São Paulo, v. 9, n. 1, p. 106-125, 2012.

OCDE - ORGANIZAÇÃO DE COOPERAÇÃO E DESENVOLVIMENTO ECONÔMICO. Manual de Oslo: diretrizes para coleta e interpretação de dados sobre inovação. 3. ed. Brasília: FINEP, 2005. Disponível em: <http://www.uesc.br/nucleos/nit/manualoslo.pdf >. Acesso em: 03 fev. 2015.

OTLEY, D. Performance management: a framework for management control systems research. Management accounting research, v. 10, n. 4, p. 363-382, 1999.

OYADOMARY, J. C. T.; CARDOSO; R. L.; SILVA, B. O. T. S.; PEREZ, G. Sistemas de controle gerencial: estudo de caso comparativo em empresas inovadoras no Brasil. Revista Universo Contábil, Blumenau, v. 6, n. 4, p. 21-34, 2010.

PALADINO, G. Introdução. In: FAYET, E. A. (Org.). Gerenciar a inovação: um desafio para as empresas. Curitiba: IEL, 2010. p. 11-16.

RAUPP, F. M.; BEUREN, I. M. Metodologia da pesquisa aplicável às ciências sociais. In: BEUREN, I. M. (Org.). Como elaborar trabalhos monográficos em contabilidade: teoria e prática. 3. ed. e 4. reimpr. São Paulo: Atlas, 2009. p. 76-97. 
REIS, D. R. Gestão da inovação tecnológica. São Paulo: Manole, 2004.

REVELLINO, S.; MOURITSEN, J. The multiplicity of controls and the making of innovation. European Accounting Review, Brussels, v. 18, n. 2, p. 341-369, 2009.

RICHARDSON, R. J. Pesquisa social: métodos e técnicas. São Paulo: Atlas, 1999.

ROUSSEL, P. A.; SAAD, K. N.; ERICKSON, T. J. Third generation R\&D: managing the link to corporate strategy. Boston: Harvard Business School Press, 1991.

SANTOS, P. S. A.; ROCHA, I.; HEIN, N. Utilização da entropia informacional na seleção de indicadores financeiros mais relevantes para tomada de decisão no setor público: o caso dos estados brasileiros. Perspectivas em Ciência da Informação, Belo Horizonte, v. 19, n. 2, p. 83-105, 2014.

SARKAR, S. Inovação: metamorfoses, empreendedorismo e resultados. In: TERRA, J. C. C. (Org.). Inovação quebrando paradigmas para vencer. São Paulo: Saraiva, 2007. p. 27-31.

SCHUMPETER, J. A. Development. Journal of Economic Literature, USA, v. 43, n. 1, p. 108-120, 2005.

SIMONS, R. The role of management control systems in creating competitive advantage: new perspectives. Accounting, Organizations and Society, Clifton, UK, v. 15, n. 112, p. 127-143, 1990.

. Control in an age of empowerment. Harvard Business Review, Boston, v. 73, n. 2, p. $80-88,1995$ a.

. Levers of control. Boston: Harvard Business School Press, 1995b.

SOLY, B. et al. Os incentivos fiscais à inovação tecnológica. In: GARCIA, C. (Org.). Lei do Bem: como alavancar a inovação com a utilização de incentivos fiscais. São Paulo: Ed. Pillares, 2014. p. 39-79.

TIDD, J.; BESSANT, J.; PAVITT, K. Gestão da Inovação. 3. ed. Porto Alegre: Bookman, 2008.

UTZIG, M. J. S.; BEUREN, I. M. Relação do uso interativo do sistema de controle gerencial com diferentes modelos de gestão de inovação. Revista de Administração e Inovação, São Paulo, v. 11, n. 4, p. 260-286, 2015.

VAN DE VEN, A. H.; POOLE, M. S. Methods for studying innovation processes. In: VAN DE VEN, A. H.; ANGLE, H. L.; POOLE, M. S. (Ed.). Research on the management of innovation: The Minnesota studies. New York: Oxford University Press. 2000. p. 31-54.

WELSCH, G. A.; HILTON, R.; GORDON, P. Budgeting: profit planning and control. 5. ed. New York: Prentice Hall, 1988.

Recebido em: 12-10-2016

Aprovado em: 24-04-2017

Avaliado pelo sistema double blind review.

Editor: Elmo Tambosi Filho

Disponível em http://mjs.metodista.br/index.php/roc 